\title{
The Need for Continued Development of Ricin Countermeasures
}

\author{
Ronald B. Reisler ${ }^{1}$ and Leonard A. Smith ${ }^{2}$ \\ ${ }^{1}$ Division of Clinical Medicine, Clinical Research Management Inc., Team Ke'aki Tech, United States Army Medical Research Institute \\ of Infectious Diseases, 1425 Porter Street, Fort Detrick, MD 21702-5011, USA \\ ${ }^{2}$ Division of Toxinology, United States Army Medical Research Institute of Infectious Diseases, 1425 Porter Street, Fort Detrick, MD \\ 21702-5011, USA
}

Correspondence should be addressed to Ronald B. Reisler, ronald.reisler@hhs.gov

Received 1 August 2011; Accepted 10 January 2012

Academic Editor: Phillip R. Pittman

Copyright (C 2012 R. B. Reisler and L. A. Smith. This is an open access article distributed under the Creative Commons Attribution License, which permits unrestricted use, distribution, and reproduction in any medium, provided the original work is properly cited.

Ricin toxin, an extremely potent and heat-stable toxin produced from the bean of the ubiquitous Ricinus communis (castor bean plant), has been categorized by the US Centers for Disease Control and Prevention (CDC) as a category B biothreat agent that is moderately easy to disseminate. Ricin has the potential to be used as an agent of biological warfare and bioterrorism. Therefore, there is a critical need for continued development of ricin countermeasures. A safe and effective prophylactic vaccine against ricin that was FDA approved for "at risk" individuals would be an important first step in assuring the availability of medical countermeasures against ricin.

\section{Introduction}

In the aftermath of September 11, 2001, it has become increasingly clear that there is a need to enhance readiness against attack from both state sponsors and nonstate sponsors of bioterrorism. Ricin toxin, an extremely potent and heat-stable toxin produced from the bean of the Ricinus communis (castor bean plant) [1], has been categorized by the US Centers for Disease Control and Prevention (CDC) as a category B biothreat agent for biological warfare and bioterrorism [2]. In fact, according to Cookson and Nottingham, ricin was code named compound W and considered for weaponization during the US offensive Biological Warfare Program [3]. The US intelligence community believes that ricin was a component of the biowarfare program of the former Soviet Union, Iraq, and possibly other countries as well $[4,5]$.

Ricin toxin is relatively easy to produce and potentially lethal when delivered orally, intramuscularly, or through inhalation [4]. While the primary large-scale threat to US military personnel would be through powdered material that could be inhaled, ricin has been used successfully to assassinate individuals, to carry out suicide, and in 2003-2004, to terrorize US postal and Senate workers [4]. This paper reviews the rationale for development of ricin countermeasures and the progress toward achieving effective ricin countermeasures.

\section{Background}

Ricin is a 65 kilodalton $(\mathrm{kDa})$ polypeptide toxin comprised of two dissimilar polypeptide chains (an A-chain and a B-chain) held together by a disulfide bond $[1,4,5]$. The A-chain, $\sim 32 \mathrm{kDa}$, targets the ribosome and is therefore a potent inhibitor of protein synthesis $[4,5]$. Consequently, the A-chain has been classified as a ribosome-inactivating protein (RIP) $[4,5]$. The B-chain, $\sim 34 \mathrm{kDa}$, is a galactose or an $\mathrm{N}$-acetylgalactosamine-binding lectin that attaches to cell-surface receptors $[4,5]$. After binding and subsequent endocytosis, the holotoxin travels through the Golgi apparatus to the endoplasmic reticulum where the disulfide bond linking the $\mathrm{A}$ and $\mathrm{B}$ chains is reduced. Once the disulfide bond is broken, the A-chain molecule is transported to the cytosol where it inactivates the ribosome. In fact, just one ricin molecule per cell may be sufficient to permanently inhibit that cell from performing essential cellular protein synthesis [6].

Ricin holotoxin is lethal in mice, rabbits, and monkeys at parenteral doses of 5-25 $\mu \mathrm{g} / \mathrm{kg}$ [4]. By inhalation, ricin has an $\mathrm{LD}_{50}$ in mice, rabbits, and monkeys of 3-17 $\mu \mathrm{g} / \mathrm{kg}$, and by 
ingestion it has an $\mathrm{LD}_{50}$ of $20 \mathrm{mg} / \mathrm{kg}$ [4]. When ricin toxin $\mathrm{A}$ (RTA) chain is separated from ricin toxin B (RTB) chain and is administered parenterally to mice, it has limited toxicity at lower doses. RTA is approximately 1000 -fold less toxic than natural ricin at lower doses when administered parentally to mice [7].

Ricin toxin is a potential threat to humans by three distinct routes: aerosolized ricin via the pulmonary system, food and water via the gastrointestinal system, and bioweaponized munitions including improvised explosive devices, via skin wounds $[8,9]$. For more than 120 years, researchers have been working on ways to both develop prophylaxis against ricin exposure and to effectively treat ricin postexposure [4].

\section{Early Work on Ricin Vaccine and Pretreatment for Ricin Exposure}

Initially, as early as the 1890s, Paul Ehrlich vaccinated mice with oral doses of ricin and then subsequently challenged the mice with subcutaneous lethal doses of ricin [10]. Later, in the 1940s, a formalin-inactivated holotoxin vaccine was developed by the US Army that enhanced survival in animals [11]. This vaccine candidate did not progress past preclinical testing. Pretreating animals with passive transfer of either IgG polyclonal antibody [12-14] or monoclonal directed against RTA, appeared to effectively protect them from lethal parenteral challenge to ricin [15-17]. Protection against a lethal dose of aerosolized ricin with passive transfer of either IgG polyclonal or monoclonal antibody directed against RTA has proved to be more difficult to achieve.

\section{Progress toward a Prophylactic Ricin Vaccine}

4.1. US Army Ricin Vaccine Development (1990s). Past attempts to produce a ricin vaccine with an Alhydrogel-adsorbed ricin toxoid [18-20] and a deglycosylated RTA (dgRTA) vaccine (Lot 01-0419964, PerImmune) [20-22] suggested that although both products can induce protective immunity against the toxin in animals, their use as vaccines was limited by safety concerns raised during preclinical development, the tendency to self-aggregate and precipitate from solution, and difficulties associated with process and product characterization during manufacturing. Thus, these vaccine candidates were limited to pre-clinical testing and never progressed to human clinical trials.

4.2. RiVax Recombinant Vaccine. RiVax, an investigational recombinant protein RTA vaccine, was developed based on studies with ricin and RTA $[23,24]$. RiVax is essentially RTA with two simple amino-acid substitutions, one in the LDV amino acid sequence $\{$ amino acid residues $74-76\}$, hypothesized to play a key role in intact RTA-induced Vascular Leak Syndrome (amino acid 76: valine replaced by methionine), and the other in a ribotoxic site (amino acid 80: tyrosine replaced with alanine) [23]. RiVax was found to have sufficient preclinical safety data to proceed to a human phase I doseescalating study $[24,25]$. The human phase I study was de- signed as follows: 15 healthy volunteers (three groups of five) were vaccinated three times with intramuscular (IM) RiVax (doses were either $10 \mu \mathrm{g}, 33 \mu \mathrm{g}$, or $100 \mu \mathrm{g}$ ) at monthly intervals [25]. Vitetta et al. demonstrated that RiVax was safe and elicits neutralizing antibody in a cell based assay. Vitetta et al. reported that in the low-dose group, one out of five had neutralizing antibody, in the intermediate dose group four out of five had neutralizing antibody, and in the high-dose group five out of five had neutralizing antibody. In the two higher dose groups, neutralizing antibody titers were similar but somewhat modest. Vitetta et al. estimated that the vaccine could protect against an injected dose of ricin of $(0.3-3.0 \mathrm{mg})$ or approximately 1 to 10 -fold the human $\mathrm{LD}_{50}$. However, the duration of antibody titers after three vaccinations (range: 14-127 days) was suboptimal and not related to dosing group.

While initial RiVax phase I results were encouraging, vaccine formulation and stability remain problematic. Vitetta et al. required the use of four different vaccine lots during the course of the initial 15 subject phase I study [25]. Moreover, RiVax formulation required storage at $-70^{\circ} \mathrm{C}$ in a buffer containing 50\% glycerol. Therefore, Smallshaw and Vitetta subsequently developed a lyophilized formulation of the vaccine that retained immunogenicity when stored at $4^{\circ} \mathrm{C}[26$, 27].

A second RiVax phase I trial in 30 subjects at three different dose levels, utilizing an alum adjuvant formulation, was supported by an FDA Orphan Products grant to University of Texas Southwestern (UTSW). As of March 29, 2011, enrollment for the second phase I trial [28] was complete [29]. In their SEC annual report filing, Soligenix reported that preliminary results from the second phase 1 trial indicated that RiVax appeared safe at all doses tested. To date, human immunogenicity data have not been reported. Soligenix also reported that they initiated a comprehensive program to evaluate the efficiency of RiVax in nonhuman primates at the Tulane University Health Sciences Center [29].

4.3. RVEc Recombinant Vaccine. USAMRIID has developed a recombinant RTA vaccine 1-33/44-198 (rRTA 1-33/44-198) (RVEc) produced in Escherichia coli [30-32]. Based on preclinical studies, including a pivotal repeated-dose toxicology study in New Zealand white rabbits conducted under GLP [33], this product was determined to have a reasonable safety profile for use in human studies. The pre-clinical testing demonstrated no detectable ribosome inactivating protein (RIP) activity [33] or evidence of vascular leak syndrome (VLS) [34]. A phase I $(N=30)$ first in human escalating, multiple-dose, and single-center study to evaluate the safety and immunogenicity of RVEc was launched at USAMRIID, Fort Detrick MD, in April 2011. The phase I study is expected to be completed by the first half of $2013[35,36]$.

\section{Monoclonal Antibody Pre-Clinical Development and Proof of Concept for Postexposure Prophylaxis}

Neal et al. reported that passive prophylactic administration (intraperitoneal $\{\mathrm{IP}\}$ injection) of GD12 (a murine IgG1 
monoclonal antibody (Mab) —anti-RTA) when administered $24 \mathrm{~h}$ prior to challenge was sufficient to protect mice against intraperitoneal ricin challenge of $5 \mathrm{LD}_{50}$ [37]. Neal et al. further demonstrated that GD12 protected mice utilizing a backpack tumor delivery system after intragastric ricin challenge of $5 \mathrm{mg} / \mathrm{kg}$. Neal et al. did not test GD12 in the setting of post-exposure prophylaxis. In a follow-up study, Neal et al. demonstrated similar protection in mice when two other monoclonal antibodies, R70 (anti-RTA) and 24B11 (anti-RTB), were passively administered using the so-called backpack tumor model [38]. The mice then survived challenge with intragastric ricin $5 \mathrm{mg} / \mathrm{kg} 12-24 \mathrm{~h}$. In addition, R70 Mab protected mice after it was administered IP, $12-24 \mathrm{~h}$ before intragastric ricin challenge of $5 \mathrm{mg} / \mathrm{kg}$.

Prigent et al. demonstrated that a combination of three Mabs ( 2 anti-RTB and 1 anti-RTA) to ricin protected mice when the three Mabs were administered intravenously (IV) within $7.5 \mathrm{~h}$ after ricin intranasal challenge of $5 \mathrm{LD}_{50}$ [39]. Thus, it would appear that Prigent et al. demonstrated a proof of concept for effective post-exposure prophylaxis to lethal-dose intranasal challenge to ricin [39].

\section{Small Molecule Inhibitors: Preclinical Development and Pre-Exposure Prophylaxis}

Stechmann et al. have recently reported on the successful identification of a selective small molecule inhibitor, Retro2 , that protected mice in a ricin nasal challenge model, when Retro-2 was administered IP one hour prior to challenge [40]. This small molecule inhibitor is attractive in that it does not act on the toxin itself, but rather it blocks retrograde trans port of the toxin, a host-toxin interaction. Stechmann et al. argue that since Retro-2 blocks retrograde transport and does not act on the toxin or the host cell itself, there is a decreased likelihood that significant drug resistance will develop to Retro-2. Moreover, Retro-2 appears to be nontoxic to HeLa cells. Small molecules inhibitors offer another promising potential avenue for the development of effective prophylaxis against ricin toxin exposure [41].

\section{Rationale for Continued Development of Ricin Countermeasures}

Schep et al. have recently argued somewhat simplistically that although ricin is toxic, it does not deserve to be a priority in biological countermeasure development [9]. They maintain that bioterrorists do not possess the technical and logistical skills necessary to formulate and mill ricin powder. St. Georgiev similarly maintained that ricin is more compatible with a tool of assassination instead of a weapon of mass destruction [42]. However, Radosavljevic and Belojevic have recently formulated a much more compelling and comprehensive approach to biodefense prioritization and risk assessment [8]. Their approach incorporates all of the potential biothreat agents on the CDC biothreat agent list. Furthermore, their model considers quantitative and qualitative parameters in assessing risk and has four main components: perpetrators (government institutions/organizations, terrorist groups, individuals); agent (CDC categories A, B, and C); means and media of delivery (air, food, water, fomites); target (direct and indirect) [8].

The US Armed Forces, Department of Homeland Security (DHS) personnel, first responders, FBI, local law enforcement personnel, CDC/HHS, the Environmental Protection Agency (EPA), and environmental clean-up crews all need adequate protection against potential biological warfare and bioterrorism. Therefore, there is a critical need for continued development of ricin countermeasures.

\section{Conclusion}

While small molecule inhibitors and Mabs for post-exposure treatment are still being evaluated in a pre-clinical setting, RiVax has been studied in two phase I clinical trials, and RVEc is currently in a phase I human trials. A safe and effective prophylactic vaccine against ricin that is FDA approved for "at risk" individuals should be an important first step in countering this 120 -year-old threat.

\section{Acknowledgments}

The authors would like to acknowledge the Defense Threat Reduction Agency (DTRA), Joint Science and Technology Office for Chemical and Biological Defense (JSTO-CBD) for their continued support of the development of the RVEc vaccine. The views and opinions expressed in this paper are those of the authors and do not reflect official policy or position of the Department of the Army, Department of Defense, or the US Government. The opinions or assertions contained herein are those of the authors and are not to be construed as official policy or as reflecting the views of the Department of the Army or the Department of Defense.

\section{References}

[1] G. A. Balint, "Ricin: the toxic protein of castor oil seeds," Toxicology, vol. 2, no. 1, pp. 77-102, 1974.

[2] Centers for Disease Control and Prevention, "Biological and chemical terrorism: strategic plan for preparedness and response," Morbidity and Mortality Weekly Report, vol. 49, no. RR-4, pp. 1-14, 2000.

[3] J. Cookson and J. Nottingham, A Survey of Chemical and Biological Warfare, vol. 6, Monthly Review Press, New York, NY, USA, 1969.

[4] M. A. Poli, C. Roy, K. D. Huebner, D. R. Franz, and N. K. Jaax, "Ricin," in Medical Aspects of Biological Warfare, Z. F. Dembek, Ed., pp. 323-335, Borden Institute, Washington, DC, USA, 2007.

[5] J. Audi, M. Belson, M. Patel, J. Schier, and J. Osterloh, "Ricin poisoning a comprehensive review," Journal of the American Medical Association, vol. 294, no. 18, pp. 2342-2351, 2005.

[6] K. S. Eiklid, S. Olsnes, and A. Pihl, "Entry of lethal doses of abrin, ricin and modeccin into the cytosol of HeLa cells," Experimental Cell Research, vol. 126, no. 2, pp. 321-326, 1980.

[7] A. M. Soler-Rodriguez, J. W. Uhr, J. Richardson, and E. S. Vitetta, "The toxicity of chemically deglycosylated ricin Achain in mice," International Journal of Immunopharmacology, vol. 14, no. 2, pp. 281-291, 1992. 
[8] V. Radosavljevic and G. Belojevic, "A new model of bioterrorism risk assessment," Biosecurity and Bioterrorism, vol. 7, no. 4, pp. 443-451, 2009.

[9] L. J. Schep, W. A. Temple, G. A. Butt, and M. D. Beasley, "Ricin as a weapon of mass terror-separating fact from fiction," Environment International, vol. 35, no. 8, pp. 1267-1271, 2009.

[10] W. T. Porter, An Introduction to Physiology, The University Press, Cambridge, Mass, USA, 1906.

[11] A. C. Cope, Ricin in Summary Technical Report of Division 9 on Chemical Warfare and Related Problems, chapter 12, Office of Scientific Research and Development, Washington, DC, USA, 1946, Parts I-II. National Defense Research Committee.

[12] M. A. Poli, V. R. Rivera, M. L. M. Pitt, and P. Vogel, "Aerosolized specific antibody protects mice from lung injury associated with aerosolized ricin exposure," Toxicon, vol. 33, p. 289, 1996.

[13] M. A. Poli, V. R. Rivera, M. L. M. Pitt, and P. Vogel, "Aerosolized specific antibody protects mice from lung injury associated with aerosolized ricin exposure," Toxicon, vol. 34, no. 9, pp. 1037-1044, 1996.

[14] P. V. Lemley, P. Amanatides, D. Creasia, J. Ruvo, A. O’Neill, and D. C. Stafford, "Chicken antitoxin neutralizes ricin in vitro and in vivo," Toxicon, vol. 31, p. 527, 1993.

[15] P. V. Lemley and D. C. Wright, "Active immunization after passive monoclonal antibody and ricin toxin challenge," Toxicon, vol. 30, p. 531, 1992.

[16] P. V. Lemley, P. Amanatides, and D. C. Wright, "Identification and characterization of a monoclonal antibody that neutralizes ricin toxicity in vitro and in vivo," Hybridoma, vol. 13, no. 5, pp. 417-421, 1994.

[17] P. V. Lemley and D. C. Wright, "Mice are actively immunized after passive monoclonal antibody prophylaxis and ricin toxin challenge," Immunology, vol. 76, no. 3, pp. 511-513, 1992.

[18] A. Assaad, J. Hewetson, O. Parker et al., "A ricin toxoid attenuates acute pulmonary toxicity and improves survival in rats exposed to a lethal dose of ricin aerosol," Toxicon, vol. 33, p. 277, 1995.

[19] J. F. Hewetson, V. R. Rivera, P. V. Lemley, M. L. Pitt, D. A. Creasia, and W. L. Thompson, "A formalinized toxoid for protection of mice from inhaled ricin," Vaccine Research, vol. 4, no. 4, pp. 179-187, 1995.

[20] R. B. Reisler, "Development and pre-clinical evaluation of a recombitant ricin vaccine (RVEc)," in Proceedings of the 9th ASM Biodefense and Emerging Diseases Research Meeting, Poster 210 (H), Washington, DC, USA, February 2011.

[21] J. F. Hewetson et al., "Immune response and protection of rats and mice from ricin aerosol exposure after vaccination with deglycosylated ricin A chain," Fundamental and Applied Toxicology, vol. 30, supplement, article 59, 1996.

[22] P. V. Lemley, D. A. Creasia, M. Plesha, D. Walters, and D. O'Neill, "Ricin sub-unit vaccination in mice and protection from challenge," Toxicon, vol. 32, pp. 545-546, 1994.

[23] J. E. Smallshaw, A. Firan, J. R. Fulmer, S. L. Ruback, V. Ghetie, and E. S. Vitetta, "A novel recombinant vaccine which protects mice against ricin intoxication," Vaccine, vol. 20, no. 27-28, pp. 3422-3427, 2002.

[24] J. E. Smallshaw, J. A. Richardson, S. Pincus, J. Schindler, and E. S. Vitetta, "Preclinical toxicity and efficacy testing of RiVax, a recombinant protein vaccine against ricin," Vaccine, vol. 23, no. 39, pp. 4775-4784, 2005.

[25] E. S. Vitetta, J. E. Smallshaw, E. Coleman et al., "A pilot clinical trial of a recombinant ricin vaccine in normal humans," Proceedings of the National Academy of Sciences of the United States of America, vol. 103, no. 7, pp. 2268-2273, 2006.
[26] J. E. Smallshaw and E. S. Vitetta, "A lyophilized formulation of RiVax, a recombinant ricin subunit vaccine, retains immunogenicity," Vaccine, vol. 28, no. 12, pp. 2428-2435, 2010.

[27] P. S. Marconescu, J. E. Smallshaw, L. M. Pop, S. L. Ruback, and E. S. Vitetta, "Intradermal administration of RiVax protects mice from mucosal and systemic ricin intoxication," Vaccine, vol. 28, no. 32, pp. 5315-5322, 2010.

[28] Phase 1B Study of RiVax. ClinicalTrials.gov, 2011 http://www. clinicaltrials.gov/ct2/show/NCT00812071?term=rivax\&rank= 1.

[29] Soligenix Annual Report 2010, 2011, http://www.sec.gov/ Archives/edgar/data/812796/000121390011001567/ f10k2010_soligenix.htm.

[30] M. A. Olson, J. H. Carra, V. Roxas-Duncan, R. W. Wannemacher, L. A. Smith, and C. B. Millard, "Finding a new vaccine in the ricin protein fold," Protein Engineering, Design and Selection, vol. 17, no. 4, pp. 391-397, 2004.

[31] J. H. Carra, R. W. Wannemacher, R. F. Tammariello et al., "Improved formulation of a recombinant ricin A-chain vaccine increases its stability and effective antigenicity," Vaccine, vol. 25, no. 21, pp. 4149-4158, 2007.

[32] M. M. Meagher, J. G. Seravalli, S. T. Swanson et al., "Process development and cGMP manufacturing of a recombinant ricin vaccine: an effective and stable recombinant ricin a-chain vaccine-RVEc," Biotechnology Progress, vol. 27, no. 4, p. 1036, 2011.

[33] D. E. McLain, T. L. Horn, C. J. Detrisac, C. Y. Lindsey, and L. A. Smith, "Progress in biological threat agent vaccine development: a repeat-dose toxicity study of a recombinant ricin toxin A-chain (rRTA) 1-33/44-198 vaccine (RVEc) in male and female New Zealand white rabbits," International Journal of Toxicology, vol. 30, no. 2, pp. 143-152, 2011.

[34] A. Porter, G. Phillips, L. Smith et al., "Evaluation of a ricin vaccine candidate (RVEc) for human toxicity using an in vitro vascular leak assay," Toxicon, vol. 58, no. 1, pp. 68-75, 2011.

[35] RVEc Phase I Human Clinical Trial, 2011, http://www. usamriid.army.mil/newsroom.cfm.

[36] Safety and Immunogenicity Study of Recombinant Ricin Toxin A-Chain Vaccine (RVEc), 2011, http://www.clinicaltrials.gov/ct2/show/NCT01317667?term $=$ rvec\&rank=1.

[37] L. M. Neal, J. O’Hara, R. N. Brey, and N. J. Mantis, "A monoclonal immunoglobulin $\mathrm{G}$ antibody directed against an immunodominant linear epitope on the ricin A chain confers systemic and mucosal immunity to ricin," Infection and Immunity, vol. 78, no. 1, pp. 552-561, 2010.

[38] L. M. Neal, E. A. McCarthy, C. R. Morris, and N. J. Mantis, "Vaccine-induced intestinal immunity to ricin toxin in the absence of secretory IgA," Vaccine, vol. 29, no. 4, pp. 681-689, 2011.

[39] J. Prigent, L. Panigai, P. Lamourette et al., "Neutralising antibodies against Ricin Toxin," Plos ONE, vol. 6, no. 5, Article ID e20166, 2011.

[40] B. Stechmann, S. K. Bai, E. Gobbo et al., "Inhibition of retrograde transport protects mice from lethal ricin challenge," Cell, vol. 141, no. 2, pp. 231-242, 2010.

[41] P. G. Wahome, J. D. Robertus, and N. J. Mantis, "Small-molecule inhibitors of ricin and shiga toxins," Current Topics in Microbiology and Immunology, vol. 357, pp. 179-207, 2012.

[42] V. St. Georgiev, "National institute of allergy and infectious diseases," in Impact on Global Health, vol. 2, pp. 274-277, Humana Press, New York, NY, USA, 2009. 


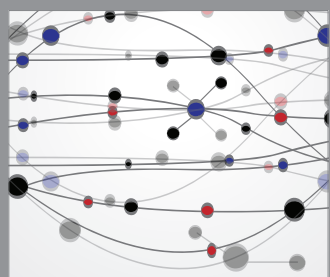

The Scientific World Journal
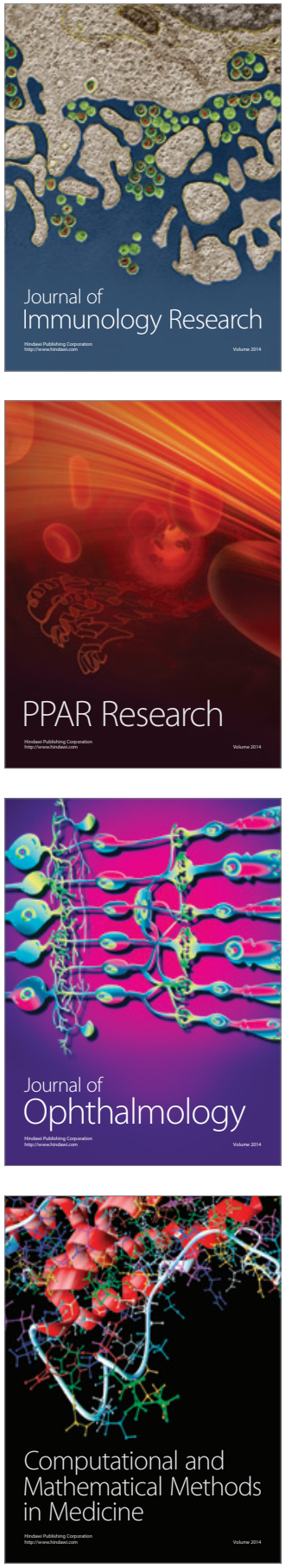

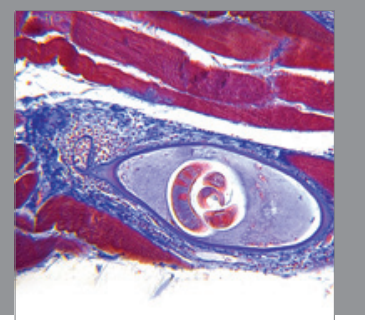

Gastroenterology

Research and Practice
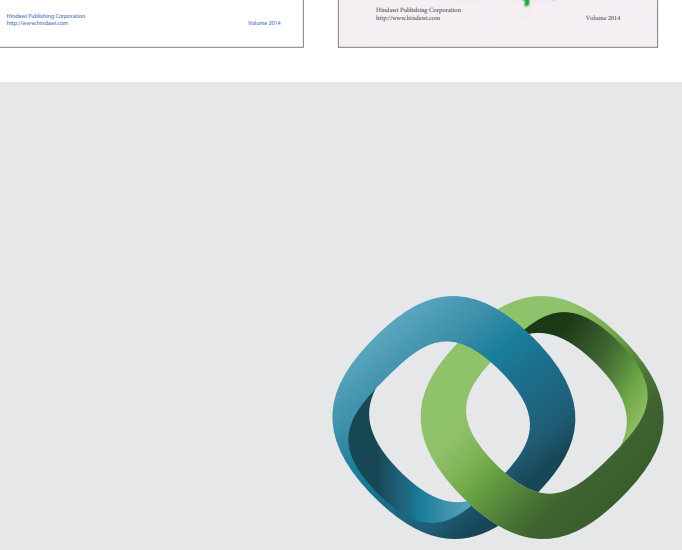

\section{Hindawi}

Submit your manuscripts at

http://www.hindawi.com
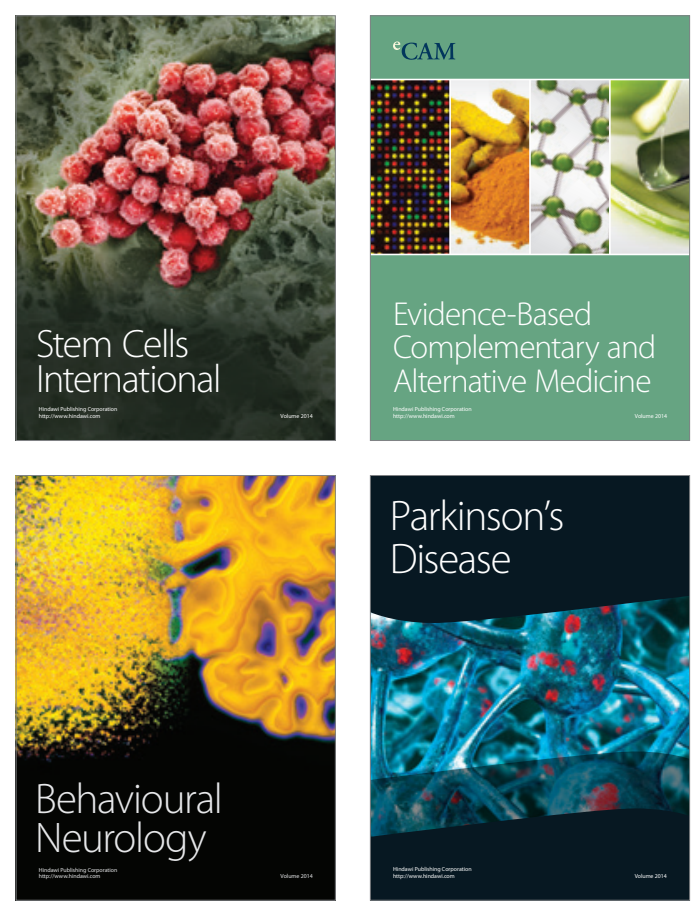

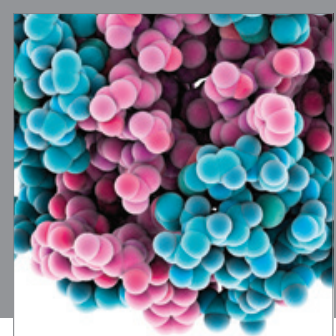

Journal of
Diabetes Research

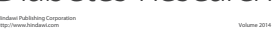

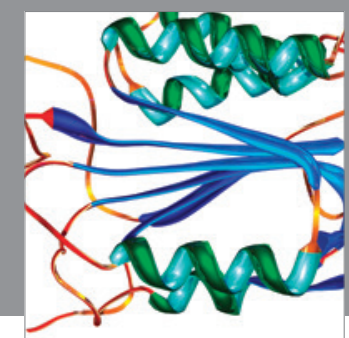

Disease Markers
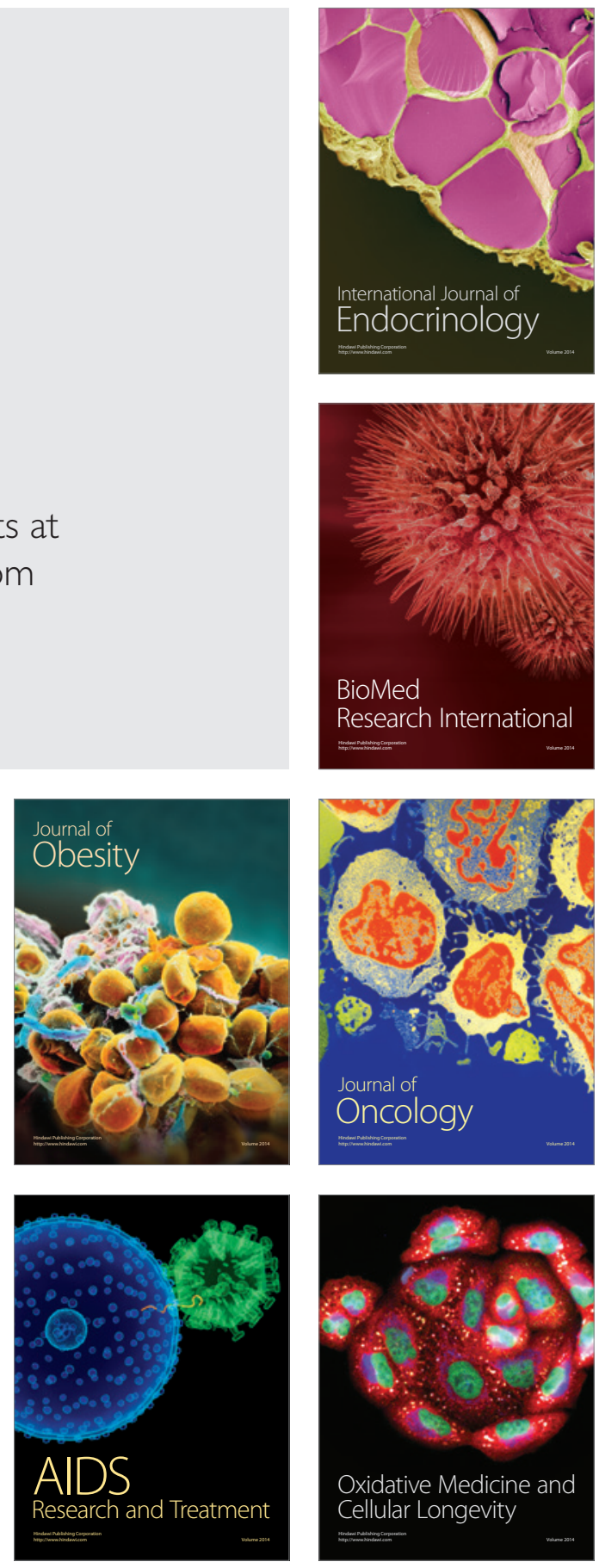